\title{
Use "Trinity" to Promote the Teaching Reform of Mechanical Design
}

\section{Course}

\author{
Pan Yuqing ${ }^{1}$, Lu Zongye ${ }^{1}$ \\ ${ }^{1}$ Guangxi Technological College of Machinery and Electricity, Nanning, Guangxi 530007, China
}

Keywords: Mechanical design; Teaching reform; Classroom teaching; Practical teaching; Extra-curricular innovation

\begin{abstract}
The mechanical design course is an essential part of mechanical design teaching. To improve the teaching quality plays a very important role in cultivating students' ability to analyze and solve engineering problems. Based on the author's learning and coaching experience, this paper analyzes current teaching problems in mechanical design course and proposes the trinity teaching method. That means the author should discuss teaching reform from classroom teaching, practical teaching and extracurricular innovation training. This paper has some help to enhance students' engineering awareness and innovation capacity.
\end{abstract}

\section{Introduction}

Mechanical design course is a very practical engineering foundation course, following theoretical mechanics, mechanics of materials, mechanical drawing and other professional mechanical courses, which serves as a link between the past and future learning. In the study of mechanical design course, students need to master basic design theory and methods of common parts and conduct basic skills with teaching practice. This will gradually improve their theoretical level, innovation capacity and problem-analysis and problem-solving skills, which lays a broad and solid foundation for the smooth transition to the professional courses and mechanical product design. In order to meet the requirements of knowledge-based economy and high-tech development in 21st century, mechanical design teaching must transform imparting knowledge and talent training model to quality education model. That means to cultivate students' ability to take the initiative to acquire and apply knowledge and make them have independent thinking and innovation capacity. This article does some useful exploration on teaching reform and innovative cultivation from the perspective of classroom teaching, practical teaching and extracurricular training.

\section{Problems in Current Teaching of Mechanical Design Course}

Teaching content in mechanical design course includes the design theory and design method of a variety of common parts. This course is to make students master specific methods of design calculation of common parts and the more important thing is to make students learn how to deal with more complex engineering problems with a relatively simplified theoretical formula. The course is an important professional basic course for students majoring mechanical engineering. This course with its strong practicality and involving a wide range of knowledge plays a very important role in cultivating mechanical engineering students' capacity to analyze and deal with practical problems. However, there exist some problems in the teaching mechanical design course. First, the 
teaching concept plays a directive and leading role in teaching, but the traditional teaching concept emphasizes too much on the systematic and complete knowledge and ignores the ability cultivation. This leads to phenomenon that values theory more than practice, values research more than design, values profoundness more than comprehensiveness and values indoctrination more than self education. Demand for trained people and business are incompatible. Second, the course content is disconnected with engineering, which is a simple teaching of basic theory knowledge. This course lacks engineering practice teaching and ignores the specific application in engineering practice. For example, some students can do very well in after-school exercise in books, but they feel helpless when encounter engineering problems in reality. Third, there is a lack of innovative teaching methods. The teaching method is still mainly one-way instillation method where students can only passively participate. The classroom atmosphere is not active and the students' interest is not high. Their innovative thinking is lagged. Fourth, curriculum evaluation system takes the closed-book exam as the sole standard to evaluate students' abilities, which lacks assessment on application of knowledge, students' practical ability and the course process.

\section{Reform of Classroom Teaching}

Teaching content. Mechanical design course is mainly designed around the basic theories and methods of mechanical common parts. It is rich in content and it is difficult to get started for students because of its fragmentary knowledge. To enable students to master this course, we always focus on the main line of teaching, Working Principle - Failure Mode - Force Analysis - Strength Calculation - Physical Design. On curriculum arrangement, we take the transmission parts, axis structure design and stress analysis and strength calculation of bolt group connection as the key content and focus on students' mastery of understanding of basic concepts and basic design methods. We cut and make appropriate adjustments in formula derivation and origin experience curve which do not improve students' engineering capability. Furthermore, we enhance the content of teaching practice and pay attention to contact the actual production. At the same time, we highlight the selected materials, structure and design parameters of common parts and increase the innovative design to strive to cultivate students' ability to apply theoretical knowledge to analyze and solve practical engineering problems.

Teaching Methods. In teaching methods, we abandoned the cramming education teaching methods and using heuristic and interactive discussion teaching methods. The teaching content is based on the few, fine, broad and new principle and focuses on teaching basic design ideas and methods of common parts. We arrange 56-hours lecturing course and 8-hours discussion course. Teachers should exchanges with students and frequently ask questions in teaching process. They should inspire students to link theory with practice and apply the learned knowledge to analyze some common mechanical products. This will integrate students and teachers and make classroom atmosphere active. For example, when teachers talk about that chain drive gears cannot be too many, they may let students analyze where the wheel is off with the connection of bicycle chain drive. Class discussion is a very important teaching link to cultivate students' initiative. Class discussion allows students to participate in teaching and become the subject of learning. We set up integrated design topics to conduct class discussion or live discussion to fully mobilize the initiative of students, so that students have the opportunity to express their learning experience and insights. For example, in the teaching of integrated design of the transmission system, students propose a variety of designs with meeting the design requirements and group themselves to discuss these designs and elect representatives to express their views. They can conduct option comparison under the guidance of teachers and ultimately arrive at a correct and reasonable design result. 
Teaching measures. We should construct the web-based teaching platform in mechanical design department for students to provide online classes, electronic lesson plans, self tests, online answering and other teaching resources. This will make students conduct self-study exercise to cultivate independent analysis and problem-solving skills. In classroom teaching, teachers should combine multimedia teaching and blackboard-writing teaching together. Multimedia teaching is visual, which greatly stimulates students' interest in learning, increases the teaching amount of information and improves the teaching effect. For example, in teaching drive system, the teacher can insert a video of engineering project to use three-dimensional animation to give students a vivid and visual impression, which helps them learn how it works. In the teaching process, we do not completely abandon the blackboard writing. The key content which needs students to master should be highlighted on the blackboard to deepen students' understanding of the basic knowledge.

\section{Reform of Practical Teaching}

To cultivate students' sense of innovation and operational ability. Mechanical design department sets cognitive test of mechanical parts, the integrated test of mechanical properties, mechanical innovation experiment and other experimental projects. The cognition laboratory of mechanical parts displays a variety of institutions, common parts, innovative design examples, engines, hydraulic stents and other products. By visiting the showcases of mechanical parts and analyzing shaping machine, students have a preliminary understanding of structures and working principles of machine and mechanical parts. Mechanical properties experiment is to verify a theory or law of classroom teaching by observing experiments. The mechanical property laboratory reforms and upgrades traditional mechanical design experiences (such as tape drive, sliding bearings and so on) in terms of control and testing. It also design some new designing and comprehensive experiments (such as comprehensive design experiments of mechanical drive) to gradually strengthen the digital virtual design experiments. Through an innovation experiment of axis, we can strengthen practical training, cultivate students' innovation awareness and encourage them to put forward a variety of program designs and structural parameters designs. The innovative mechanical design experiments change students' passive position in experimental learning, encourage students to independently design pilot projects, methods and procedures, cultivate students' comprehensive ability to apply knowledge to solve problems and develop their innovative potential.

To increase elective experiments and open laboratories. Except for the basic experiments in teaching mechanical design, we should change traditional teaching methods, increase elective experimental teaching and open laboratories to fully mobilize the students' initiative. Students can independently choose a pilot project to improve design, experimental methods, processes and the existing laboratory equipment by themselves. This will increase opportunities for students to get work and cultivate students' ability to apply the theoretical knowledge to solve practical problems.

To reform course design. Course design is the last teaching link in mechanical design course and the first design issue for students majoring engineering. To encourage students to apply learned knowledge to design a simple mechanical product is very important to cultivate students' engineering design consciousness and design capability and understanding of learned knowledge in the classroom. Traditional mechanical design is generally based on the simple transmission (reducer), which is the projector and give a clear, field-proven design data and design title in the design topic. In order to give full play to the creativity of students and change students' copy, we only make some basic functional requirements for students. We demand students to design from the beginning of the program and the whole design cycle is divided into five phases (project design, overall design, detailed design, assembly drawing, design drawing and specification writing). Each 
stage needs to organize students to discuss it and they can proceed to the next stage when the project passed. This will not only deepen students' understanding of knowledge and of the design process, but also can stimulate students' enthusiasm for innovation and enable students to experience all aspects of the design process in order to cultivate students' engineering consciousness and innovation. In curriculum design teaching, we should strengthen the application of modern design tools. Set up elective courses about UG and finite element. We encourage and guide students to use three-dimensional CAD design and use CAE to conduct analog simulation. These allow students to conduct virtual verification on their own design and know well about modern design tools in the process of verification, modification and improvement.

\section{Extracurricular Innovative Training}

Innovative extracurricular training has far-reaching significance of cultivating students' engineering consciousness and capacity of innovation and team work. It is very important for students to use theories to solve practical engineering problems and for our country to foster senior technical personnel that meet the social needs. Mechanical design departments encourage students to participate in the National College Students' Creative Design Competition. In the learning stage of mechanical principles, we should organize students to watch the previous innovative design works to allow students to collect data, design program, and study related knowledge themselves. After the plan was finalized, encourage students to enter the laboratory for the overall design and structural design and use three-dimensional software to conduct analog simulation and analysis of finite element. Students should use fischer model and institutional innovation experiment platform to conduct model establishment and contact the factory for physical processing based on this.

\section{Conclusion}

Mechanical design teaching has far-reaching significance for cultivating students' engineering consciousness and capacity of innovation and teamwork. Moreover, it is very important for students to apply theories to practical problems and it is significant to improve students' problem-analysis and problem-solving skills. This article conducts a preliminary study on teaching reform of mechanical design course and the cultivation of students' innovation capacity from the perspective of classroom teaching, practical teaching and extra-curricular innovation training. Moreover, the article does a useful attempt in construction and teaching reform of excellent mechanical design courses. The author hopes to achieve good results.

\section{References:}

[1] Qiu Wenlong. Teaching Reform of Mechanical Principles and Mechanical Design Experiments [J]. Research and Exploration in Laboratory, 2004, 12: 78-81.

[2] Shao Yuanyuan, Xuan Guantao, Hou Jialin. The Reform and Practice of Basic Mechanical Design Teaching [J]. Research and Exploration in Laboratory, 2012, 05: 132-134.

[3] Zhang Chao, Ren Xiuhua, Zhao Zhichao, Geng Zongliang, Yuan Zhengjun. Modern Reform and Innovation of the Mechanical Design Experimental Teaching [J]. Experimental Technology and Management, 2006, 10: 97-100.

[4] Lu Fengyi, Xu GeNing, Zhu Jianru, Yang Wen, Kong Xiangying. The Construction and Teaching Reform of Basic Experimental Teaching Demonstration Center [J]. Experimental Technology and Management, 2006, 02: 81-83 + 89.

[5] Li Shenglin, Wang Hongping, Wei Min. A Discussion of Teaching Reform of Basic 
Experimental Teaching [J]. Experimental Technology and Management, 2005, 07: 98-99 + 102 . 